\title{
D e la família a les polítiques familiars. Vicissituds d'un recorregut
}

\author{
Lluís Flaquer \\ U niversitat Autònoma de Barcelona. D epartament de Sociologia \\ 08193 Bellaterra (Barcelona). Spain \\ Iluis.flaquer@uab.es
}

Resum

En aquest article l'autor tracta d'identificar alguns elements crucials que han influenciat el seu itinerari intel-lectual i que, per tant, han contribuït a la gènesi de les seves orientacions teòriques i de les seves pràctiques de recerca. Comenta diverses menes de recerca en les quals ha participat, el principal interès de les quals era un millor coneixement de l'estructura de la família, de l'organització de l'esfera privada i de la seva evolució en les socie tats modernes. En els darrers anys ha incorporat al seu discurs les nocions de gènere, patriarcat i individualització, i destaca el paper de l'Estat de benestar i la importància de les polítiques familiars en la mesura que tendeixen a conformar la matriu de limitacions i oportunitats de la qual sorgeixen els valors familiars.

\section{Abstract}

In this article the author tries to identify some crucial elements that have influenced his intellectual life and have therefore contribued to the genesis of his thoretical orientations and research pratices. H e discusses different kinds of research in which he was involved whose central concern was a better knowledge of family structure, of the organization of the private sphere and of their evolution in modern societies. In recent years he has introduced into his discourse the notions of gender, patriarchy and individualization and stresses the role of the welfare state and the importance of family policy in so far as they tend to shape the matrix of constraints and opportunities from which family values arise.

\section{Una formació pluridisciplinària}

En primer Iloc, voldria agrair sincerament la invitació feta pel D epartament de Sociologia de la U niversitat Autònoma de Barcelona a presentar la meva aportació a aquestes jornades de recerca. Aquest oferiment m'ha permès de portar a terme un exercici de recapitulació vital, força útil quan hom ja passa de la ratlla dels cinquanta, però que sovint no ens sol vagar, enfeinats com estem en un munt de projectes. Aquest balanç crític m'ha servit per dotar retrospectivament de coherència i de sentit la pròpia trajectòria acadèmica i investigadora i descobrir-hi continuïtats que jo mateix ignorava.

Per començar, voldria dedicar uns breus paràgrafs a comentar la meva for- 
mació acadèmica. Sens dubte, moltes de les orientacions que han marcat les meves línies de recerca arrenquen dels interessos que vaig desenvolupar durant els meus anys d'estudiant. Si hagués de qualificar d'alguna manera les característiques de la meva formació, diria que aquesta fou sobretot pluridisciplinària. Si els joves d'avui tenen l'oportunitat d'ingressar des de primer a les facultats de Sociologia, els de la meva generació no vàrem poder gaudir d'aquest privilegi. Q uan jo vaig iniciar els meus estudis a principis dels anys seixanta, a causa de la situació d'anormalitat democràtica que es vivia al eshores, a Barcelona no hi havia cap facultat de Sociologia, i les úniques opcions eren cursar la carre ra a $\mathrm{M}$ adrid 0 a l'estranger. Però, per a un jove de l'època, el problema no era tant on podia cursar la disciplina, sinó més aviat tenir un coneixement de la seva existència. J o, personalment, vaig haver de fer un llarg recorregut per tal d'arribar a la sociologia, tot passant pel dret, per la ciència política i l'antropologia. D esprés d'estudiar $D$ ret a la U niversitat de Barcelona, vaig gaudir d'una de les primeres beques concedides per la Fundació Jaume Bofill, que em permeté fer una estada a París (1967-69) i obtenir la llicenciatura en Ciències Polítiques a l'Institut d'É tudes Politiques. Fou allí on vaig entrar en contacte amb la sociologia per primera vegada, ja sia a través de companys que estudiaven a $\mathrm{N}$ anterre, ja sia a través d'assignatures cursades a l'I nstitut, on impartia la matè ria el professor $\mathrm{H}$ enri $\mathrm{M}$ endras. D e retorn a Barcelona, vaig prendre la determinació de cursar estudis de postgrau en sociologia a Anglaterra, però per diverses raons alienes a la meva voluntat no vaig poder portar a terme aquest projecte finsal curs 1974-75, quan Salvador Giner em va acollir al D epartament de Sociologia dela U niversitat de Lancaster. Els tres cursos acadèmics següents els vaig passar a la Universitat d'East Anglia, on hi havia un gran interès per la recerca pluridisciplinària sobre la família. Fou allí on, a través de la meva supervisora $M$ arie Corbin, vaig poder ampliar els meus coneixements sobre l'antropologia social, que em serviren per tal d'orientar la primera fase de la meva recerca. Voldria reivindicar aquest itinerari, que a primera vista pot resultar tortuós i representar una marrada, com un enriquiment de la meva perspectiva sociològica, que d'al guna manera s'ha vist reflectit en els meus treballs de recerca.

A continuació, voldria tractar de presentar les meves línies de recerca principals, ja que és a través d'elles que s'ha desenvolupat la meva reflexió teòrica i la meva pràctica com a investigador.

\section{Els canvis en la família troncal}

Començaréel meu recorregut evocant l'inici de la meva carrera com a investigador a Besalú i al seu entorn, una vila de la Garrotxa que vaig escollir per tal de fer-hi una monografia sobre l'evolució de la família catalana sota l'impacte de la industrialització. Aquest poble oferia una bona ocasió per comprovar sobre el terreny els canvis que s'esdevenen en un sistema familiar arran de la transformació d'al tres dimensions del conjunt de la societat. El procés d'industrialització hi fou autogenerat a partir dela inversió de capitals locals, i els treballadors 
que s'incorporaven a la indústria eren antics jornalers o camperols empobrits pel pas de l'agricultura de subsistència a la de mercat. Per tant, era possible examinar les pautes de canvi en el procés de formació familiar quan els camperols abandonaven els seus masosi es veien sotmesos a noves demandes a mesura que es dedicaven a noves ocupacions en un context urbà. Fins a finals dels anys seixanta la família troncal era el sistema prevalent entre els propietaris rurals, però també entre els aparcers que vivien a la zona de poblament dispers, mentre que al nucli urbà hi predominaven les famílies nuclears entre elsjornalers i els obrers. En aquella època exercí sobre mi una certa influència Peter L aslett, amb qui jo havia entrat en contacte a C ambridge. Lasl ett ens havia brindat una metodologia per a l'estudi de la incidència de les formes familiars a Europa en períodes històrics, però alhora havia posat en dubte l'existència de la família troncal com una fantasia de Le Play (Laslett and Wall (eds.), 1972). Les meves dades contradeien aquesta apreciació i la meva primera intenció fou rebatre els resultats de Lasl ett utilitzant la seva pròpia metodologia. A Besalú i comarca era possible consultar els censos i padrons municipals de les darreres dècades, i aquesta circumstància facilitava l'estudi del procés de nuclearització. M és tard, em vaig adonar de les insuficiències d'aquest enfocament, ja que els canvis en els paràmetres demogràfics inflaven artificialment la incidència de llars multigeneracionals, indicatives de l'existència de família troncal, i vaig decidir combinar el treball de camp antropològic amb l'anàlisi d'una mostra de decisions residencials postnupcials d'unes cinc-centes parelles. Les principals modalitats retingudes foren la virilocal, la uxorilocal i la neolocal.

La selecció de la mostra es féu de la manera següent: vaig incloure-hi només aquells individus que el 1975 vivien a la comarca de Besalú, i en vaig excloure, en canvi, els solters, els que es casaren abans de 1941 o després de 1975, així com els que es casaren entre 1941 i 1975 però posteriorment emigraren. Aquest procediment de mostreig no al eatori em permeté obtenir una sel ecció força representativa de les pautes evolutives de formació familiar. Les dades foren obtingudes mitjançant diversos procediments, tant personals com impersonals, des de la consulta de padrons i registres parroquials fins a la realització d'entrevistes en profunditat sobre històries de vida, complementades per la recollida d'informacions i de dades secundàries sobre el terreny. D 'aquesta manera, tot combinant el treball de camp antropològic amb procediments d'anàlisi quantitativa, fou possible establir quins eren els principals determinants associats amb les decisions de formació familiar en cada un dels períodes de recerca (1941-1960 i 1960-1975).

Els resultats d'aquesta recerca, en la qual vaig treballar entre 1977 i 1983, aparegueren en diverses publicacions (Flaquer, 1978, 1979a, 1984a, 1986b, 1995b). D urant la primera part del període estudiat (1941-1960) gairebé quatre cinquenes parts dels matrimonis contrets a la zona de poblament dispers portaren a la formació de famílies troncals, encara que aquesta característica la trobem més sovint entre els propietaris rics que entre els pobres i més entre els terratinents que entre els masovers o els jornalers. En el nucli urbà de Besalú, en canvi, durant aquest període només un $56 \%$ dels matrimonis conduïren 
a la formació de famílies troncals, encara que resulta difícil val orar la significació sociològica de la formació d'aquesta mena de llars multigeneracionals en una època caracteritzada per fortes privacions econòmiques i escassetat d'habitatge. O n trobem més tendència a la formació de famílies troncals és entre les categories de la població amb ocupacions autònomes (botiguers, industrials, artesans i masovers), tot i que la forma típica de matrimoni dels jornal ers sense terra, en general fadristerns, era la nuclear.

A la segona part del període estudiat (1961-1975) l'augment del nombre d'obrers i en general d'assalariats al nucli urbà de Besalú contribuí a la difusió de la família nuclear. En aquest període més de la meitat dels matrimonis $(55,5 \%)$ conduïren a la formació de famílies nuclears. Però, tanmateix, les famílies troncals es mantenen prou bé després d'experimentar un procés d'adaptació a les noves circumstàncies econòmiques i socials. No tan sols les trobem entre els autònoms com a base d'una cooperació econòmica entre pares i fills, sinó que també sorgeix una nova forma de matrimoni uxorilocal que mena a la formació d'una mena de família troncal basada en l'associació entre una filla - que no necessàriament és pubilla - i els seus pares, amb la finalitat d'incrementar el seu benestar mutu. A la zona de poblament dispers observem que la família troncal no tan sols és manté, sinó que la seva presència fins i tot es reforça - el $86,3 \%$ dels matrimonis conduïren a la formació de llars troncals- , en haver desaparegut d'aquesta demarcació les categories de la població no directament vinculades amb les explotacions agràries.

Paral·lelament al meu estudi de la família troncal, la realització de treball de camp a Besalú em permeté explorar altres línies de recerca connexes. En primer Iloc, el seguiment de les primeres eleccions democràtiques del postfranquisme en una comunitat rural en un intent de desenvolupar un enfocament que aleshores vaig anomenar «antropologia electoral»(1984c, 1991c). En segon Iloc, la meva presa de contacte amb la vida rural em féu reflexionar sobre la importància de la dimensió comunitària i sobre l'estructuració de les relacions entre el públic i el privat en els contextos premoderns i moderns. Per últim, el meu estudi dels canvis en la família troncal em portaria a altres recerques sobreel procés de nuclearització des d'una perspectiva més macrosociològica.

\section{Privacitat, comunitat $\mathrm{i}$ identitat}

En aquest apartat hi voldria incloure un conjunt de recerques desenvolupades des dels inicis dels anys vuitanta i que arriben fins a l'actualitat, el fil conductor de les quals és la divisió de la vida social en les esferes pública i privada i I'anàlisi de les formes de regulació que prevalen en cada un d'aquests àmbits. El focus d'atenció d'aquestes recerques és més la vida privada que la pública, en la mesura que constitueixen estratègies per tractar d'entendre millor la natura i la dinàmica de l'univers familiar. En aquest apartat l'interès pel canvi social continua essent una dimensió primordial, així com el sefectes que els processos de modernització tenen en la constitució de la vida privada. H i podríem distingir tres línies diferents però associades entre si: 
1. Anàlisi dels distints models de públic-privat i estudi teòric de la sociogènesi de la vida privada i dels processos socials de privatització. Aquests estudis corresponen a l'època en què vaig treballar en la meva tesi de doctorat, presentada l'any 1981 i que em permeté obtenir el títol de doctor en D ret per la U niversitat Autònoma de Barcelona. Val a dir que, si bé formalment es tracta d'una tesi jurídica, el seu contingut teòric té una orientació clarament sociològica, com també ho són les publicacions a què ha donat lloc aquesta línia de recerca (Flaquer, 1982a, 1982b, 1984b, 1986a, 1986c i 1988).

En la meva tesi doctoral, intitulada Alguns aspectes teòrics de la privaci tat, exploro diverses qüestions relatives a la constitució dels espais públic i privat en la societat moderna. En primer Iloc, examino les diverses teoritzacions clàssiques formulades per tal d'explicar el naixement i l'evolució de l'esfera privada. En segon Iloc, estudio la significació dela vida privada en la societat d'avui, com a refugi i font d'identitat en un món públic cada vegada més privat de sentit. En tercer $\|$ oc, analitzo les formes de regulació de l'esfera privada, caracteritzades per un feble control normatiu, per un perill d'anomia i per un cert pluralisme i flexibilitat de models.

2. Com a complement de la línia anterior, vaig emprendre l'estudi d'alguns clàssics del pensament social i de la seva contribució a la conceptualització de la dicotomia públic-privat. Entre ells cal destacar especial ment els següents: Ferdinand Tönnies, J.S. M ill i Adam Ferguson (Flaquer y Giner, 1979; Flaquer i Giner, 1984; Flaquer, 1983; Flaquer, 1989).

3. Anàl isi dels processos de construcció de la identitat cultural a C atalunya. Ja durant els anys noranta, aquesta línia pren un nou caire. L'èmfasi passa de la reflexió teórica sobre la societat moderna a l'anàlisi empírica d'un cas particular, el de C atalunya, centrat especialment en la construcció de la nostra identitat cultural i lingüística.

A L a cultura catalana: el sagrat i el profà (Giner, Flaquer, Busquet i Bultà, 1996), els autors exploren les potencialitats d'una concepció vertical de la cultura a còpia de dissenyar una metodologia que permeti analitzar els episodis de conflicte més significatius que marquen la construcció de la nostra identitat cultural. La conclusió és que el procés recent de gerencialització que podem detectar en la cultura catalana - el seu aspecte profà- no exclou la renovellada insistència en els debats sobre la identitat nacional - el seu aspecte sagrat- , de tal manera que aquestes dues cares de la nostra cultura poden reforçar-se mútuament.

D 'altres publicacions se centren específicament en la temàtica de la llengua (Flaquer, 1991b, 1994c, 1994d, 1998e). La publicació més important d'aquest apartat és El català, ¿llengua pública o privada? (Flaquer, 1996c). En aquest treball analitzo el resultat de cent entrevistes en profunditat fetes a cent ciutadans barcelonins sobre les vivències relatives a la social ització lingüística. 
La tesi que defenso és que les dificultats amb què es troba el català són degudes al fet que la socialització lingüística dels nouvinguts té lloc cada vegada menys en contextos primaris i comunitaris, per la qual cosa el seu aprenentatge sovint resulta associat amb motivacions instrumentals. D 'altra banda, en les interaccions entre estranys que tenen Iloc a l'espai públic el castellà tendeix a predominar a causa de la indiferenciació creixent de rols i estils de vida associats amb les identitats lingüístiques. A leshores, el castellà tendiria a imposars'hi en virtut del principi d'economia d'esforços.

\section{El procés de nuclearització}

L 'estudi sobre la família troncal a Besalú obrí la via a noves incursions en el camp de la família. Cal assenyalar especialment un treball de recerca real itzat al final de la dècada dels anys vuitanta, en el qual aflora una vegada més el meu interès pel procés de nucl earització a través de l'evolució de les formes familiars. L'experiència adquirida en l'explotació de dades centralsi padronals durant I'època de Besalú revelà la seva utilitat en aquest projecte de recerca, fet en col·laboració amb Joan Soler i finançat pel Centro de Investigaciones Sociológicas (Flaquer i Soler, 1990; Flaquer, 1990).

J a feia temps que havia constatat la importància de les bases de dades censals per a l'estudi dels fenòmens familiars (Flaquer, 1979b; C onte i Flaquer, 1983). L'anàlisi de la composició de les llars a través de les dades censals pot constituir un instrument de primera magnitud per a l'estudi de l'evolució de les formes familiars. Permanencia y cambio en la familia española és un estudi comparatiu de la composició de les llars fent servir el resultat dels censos de 1970 i 1981. Els autors varen efectuar una anàlisi de correlacions amb 165 indicadors relatius a diferents aspectes de l'estructura de la família i a altres variables socioeconòmiques i socidemogràfiques corresponentsa 1970 i 1981, que permeté detectar les principals tendències de canvi de les formes familiars. Entre els resultats cal destacar la difusió de la nuclearització en tot el territori espanyol ensems amb una relativa persistència de formes tradicionals, la qual cosa és deguda, en part, a la inèrcia demogràfica però també al caràcter familiar de la nostra societat.

\section{N oves formes de convivència: treballs de sociografia de la família}

A principis del s anys noranta l'estudi de la nuclearització es revela insuficient. D 'una banda, la família nuclear ja s'havia imposat com a model dominant en tot el territori espanyol, per bé que poguessin subsistir algunes formes tradicionals a les zones rurals. D e l'altra, començaven a entreveure's els signes de la crisi del sistema nuclear. L'aparició de nous models i formes familiars, com ara la cohabitació, les Ilars monoparentals o les unipersonals evidenciava l'e xistència de canvis en profunditat. Es tractava de continuar amb la línia de recerca anterior sobre l'evolució de les formes familiars al nostre país, però parant una atenció especial al creixement i a la difusió de les noves llars. En 
aquest sentit, cal destacar I'anàlisi de les dades de la segona edició de l'Enquesta M etropolitana de Barcelona (1990) (Flaquer, M asats i altres, 1992), la redacció del capítol de família del darrer Informe FOESSA (I glesias de U ssel, Flaquer i altres, 1994), un treball sobre la situació de la família a Barcelona encarregat per l'Ajuntament (Flaquer i Solsona, 1995) i l'estudi de la família catalana en el marc d'una recerca sobre l'estructura social finançada per I'Institut d'Estadística de C atalunya (Flaquer, 1998b, 1998c, 1998d). D 'entre aquests estudis en voldria comentar només un de sol, fet en col·laboració amb altres sociòlegs: Parejas y matrimonios: Actitudes, comportami entos y experiencias (Alberdi, Flaquer i I glesias de U ssel, 1994). Aquest Ilibre fou el resultat de l'explotació d'una enquesta realitzada per CIRES I'octubre del 1990. L'èmfasi de l'anàlisi se centrà en els processos de formació de la parella i de la família. La generació de noves variables permeté descobrir interessants associacions que fins aleshores havien estat escassament explorades. En particular, cal citar I'anàlisi del grau d'homogàmia educativa en relació amb les experiències de cohabitació, l'ús d'anticonceptius i l'evolució dels rols conjugals.

Completen aquest apartat un estudi empíric sobre la monoparentalitat (Almeda y Flaquer, 1995), en el qual els autors tracten d'avaluar la seva incidència a través de diverses fonts i metodologies, i d'altres treballs empírics sobre les transformacions de l'estructura social espanyol a i catal ana (Flaquer y Giner, 1982; Flaquer, G iner i M oreno, 1990; G iner, Flaquer, H omsi Sarasa, 1998).

\section{G ènere i mercat: família i individualització}

En aquest apartat incloc un seguit de treballs teòrics sobre les transformacions del sistema familiar en els quals sinicia la línia de recerca que condueix directament a les meves recerques actuals. El que és característic d'aquesta etapa és la introducció progressiva de les nocions de gènere i patriarcat. Avui resulta difícil concebre una sociologia de la família que prescindeixi de les recerques fetes en el camp del gènere, però també costa imaginar una sociologia del gènere que no fixi la seva atenció preferent en el camp familiar. Per tant, és comprensible que en els darrers anys haguem assistit a una convergència teòrica entre aquestes dues especialitats.

U na de les nocions que apareix amb força als meus discursos d'aquesta època és la d'individualització. En un conjunt de treballs (Flaquer, 1991, 1993a, 1993b, 1994a, 1994b, 1995c, 1995e, 1995f, 1995g, 1995h i 1996a, 1996b, 1997 i 1998a) vaig perfilant el meu pensament teòric sobre els canvis en el sistema familiar que acompanyen la segona transició demogràfica. La idea és que la mirada que projecten els demògrafs sobre el canvi familiar és insuficient, perquè la seva anàlisi se centra més en les conseqüències que en les causes dels processos que ens interessa comprendre. Per tant, cal introduir variables que tinguin una significació sociològica, com ara la d'individualització. Amb l'accés cada vegada més gran de les dones al mercat de treball i el seu ingrés progressiu a l'esfera pública s'incrementa el grau d'individual ització dins la família. Però l'emancipació de la dona no és I'única causa de l'augment de la indivi- 
dualització intrafamiliar. En general, una deles fonts d'individualització és l'acció del mercat, i la penetració de les forces del mercat dins la família potencia aquesta tendència. Així, algunes de les tasques tradicionals de la llar, com ara la preparació del menjar, poden ser parcialment confiades al mercat (menjars preparats, fast food, etc.) i l'organització del temps de lleure entorn de la pantalla del televisor evidencia també el creixement de l'entreteniment programat en forma de consum cultural. L'accés al consum massiu d'aquelles categories de la població - dones, joves, gent gran - que en certa manera restaven al marge del mercat, fa que els seus membres tendeixin a individualitzar-se.

Però la individualització no tan sols és resultat de l'acció del mercat, sinó també del'Estat. Si els membres d'aquestes categories socials es constitueixen en individus no és tan sols perquè esdevenen consumidors. En la mesura que els Estats de benestar els confereixen drets socials de ciutadania, que els donen accés a determinades prestacions socials, també els ajuden a constituir-se com a individus.

\section{Família i Estat de benestar: les polítiques públiques sobre la família}

Aquesta darrera etapa de la meva recerca representa la introducció d'elements radicalment nous ensems amb la recuperació de certes línies ja estroncades o que havien quedat en segon terme.

El capgirament d'al guns dels meus interessos de recerca coincideix amb l'inici de la meva col·laboració en un projecte d'investigació internacional. D es de 1994 assumeixo la direcció de l'equip espanyol del projecte Family Change and Family Policy, codirigit per Peter Flora ( $M$ annheimer Zentrum für Europäische Sozialforschung, M annheim, Alemanya), Sheila K amerman i Alfred Kann (C olumbia University School of Social Work, N ova York). Aquest projecte, que estudia comparativament la situació de la família en relació amb les polítiques de l'Estat de benestar en una vintena de països, donarà Iloc a la publicació de vuit volums editats per una editorial anglesa. L'equip espanyol, format per Teresa Jurado (Istituto U niversitario Europeo, Florència) i Elisabet Almeda (U niversitat Pompeu Fabra), s'encarrega de la recopilació de les dades, de la seva anàlisi i de la redacció d'un informe de síntesi sobre les polítiques familiars a E spanya, que s'integrarà en un dels volums de Ia publicació general: Peter Flora (ed.), Family C hange and Family Policy in Southern Europe, Londres: Clarendon Press (Flaquer, Almeda; i Jurado, en premsa).

El M annheimer Zentrum für Europäische Sozial forschung, està constituint a $M$ annheim (Alemanya) una base de dades sobre família i Estat de benestar, i el 1996 inicià un ambiciós programa de formació i mobilitat d'investigadors, finançat per la U nió Europea, que jo gestiono a nivell espanyol. Aquest programa, que comporta l'intercanvi d'uns trenta-cinc investigadors entre diversos centres de recerca europeus, té per objecte la formació d'un conjunt d'investigadors de diverses disciplines que trebal lin seguint línies de recerca semblants. 
La integració en aquest projecte de recerca internacional comportà diverses novetats. En primer Iloc, representà el descobriment de la dimensió europea en l'anàlisi comparativa, que en els darrers anys està prenent una important embranzida sota la impulsió del finançament de la U nió Europea. Tenir present en els estudis familiars el marc europeu suposa la constatació de la gran diversitat de sistemes familiars, de règims de benestar i de polítiques familiars, cosa que resulta molt enriquidora a l'hora de generar problemàtiques i hipòtesis de recerca. Com D urkheim ja va mostrar en El suïcidi (1897), el contrast entre les pautes de suïcidi en països amb tradicions culturals i religioses diverses disposa d'una força heurística considerable en l'explicació sociològica.

En segon Iloc, aquesta nova línia de recerca suposa la represa de la problemàtica públic-privat, mig abandonada en els darrers anys. Tanmateix, la seva recuperació exigeix sotmetre l'etapa anterior a una autocrítica:

1. Cal abordar aquesta qüestió en clau política. No es poden explicar els canvis en el món privat sense explorar les mutacions de l'esfera pública. La regulació del món privat s'ha d'examinar a partir de determinades intervencions, ja sia a través de l'acció del dret de família, ja sia a través de la influència de les prestacions socials en la constitució de l'univers familiar. L'estudi de la política familiar comparada esdevé primordial per entendre l'evolució dels diversos sistemes familiars a escala europea. N o tan sols la política familiar referma i modifica determinades pautes familiars, sinó que la variació en les demandes efectuades a l'Estat de benestar per part dels partits polítics i dels moviments socials sovint és funció dels diversos sistemes de valors que constitueixen la base de les relacions familiars.

Els actors familiars formulen les seves estratègies en funció de certs determinants estructurals que alhora permeten i/o estimulen determinats comportaments i en limiten o en coarten d'altres. Aquests determinants són especialment les forces del mercat, les disposicions legals i les prestacions de l'Estat de benestar. Q uan alguns d'aquests determinants s'alteren, es modiquen els comportaments dels actors familiars $i$, de retop, es forgen nous valors.

Aquesta és la tesi que he estat seguint en diverses publicacions (Flaquer, 1995a i 1995d). La col·laboració recent amb C ristina Brullet (Flaquer i Brullet, 1999) m'ha permès posar a prova la pertinència d'aquestes idees pel que fa al nostre país. Fent una primera aproximació en l'anàlisi de les polítiques familiars a C atalunya, examinem la influència soterrada del concepte de família que s'evidencia en la dificultat per a la formulació d'un projecte de política familiar per al nostre país. El record negatiu del franquisme i la prevalença de la concepció catòlica de repartiment de responsabilitats entre família i Administració han contribuït al manteniment d'un sistema de benestar que ja no correspon al s temps actuals, basat en la força de les obligacions de parentiu, en el qual les dones resulten ser les primeres perjudicades. 
2. L'estudi dela privacitat sense parar esment en les intervencions procedents de l'esfera pública pot contribuir a l'ocultació de la seva dimensió ideològica. L'anàlisi del curs de la privatització ens ajuda a entendre els proces sos que s'esdevenen en l'àmbit familiar, però no podem oblidar que la privacitat és també una ideologia, sostinguda des de determinades cosmovisions liberals i que constitueix la base d'un cert ordre social. Això no suposa negar l'autonomia real que els individus estan assolint en les societats modernes avançades.

Cal emfasitzar no tan sols la progressió de la privatització, sinó també l'augment de publicització. Així, si la tendència dominant en el camp del matrimoni és la seva desinstitucionalització, la filiació és sotmesa cada vega da més a un control jurídic més estricte. Per tant, és possible afirmar quela família es privatitza i se socialitza simultàniament.

3. Si la categoria de la privatització era apta per a la comprensió del procés de nuclearització, els canvis experimentats per la realitat familiar en els darrers temps s'expliquen millor a través de la d'individualització. Aquest concepte esdevé ara la categoria fonamental, tot i que no acaba d'arraconar la pertinència de la privatització. $C$ al, doncs, distingir amb cura les dues nocions.

Els canvis en la família contemporània es poden concebre, per tant, com a resultat de la intensificació del procés d'individualització. El pas de la família patriarcal, tradicional o institucional a la individualista, postnuclear, postmoderna, postpatriarcal, relacional o reflexiva, passant per la nuclear, fusional o complementària (segons els diversos apel · latius emprats) no és més que un avenç en el procés de modernització de la família (Flaquer, 1998a i 1999). Era impensable que la modernització creixent de la nostra societat deixés inalterada la institució familiar. Per modernització cal entendre el desenvolupament creixent de les dues institucions centrals de la modernitat - el mercat i l'Estat- i de la seva difusió a un nombre cada vegada més gran d'àrees socials. Fins fa relativament poc, la família i I'espai privat eren un enclavament premodern dins una societat cada vegada més sotmesa a les exigències de la modernització. En els darrers anys la família s'ha modernitzat, la qual cosa ha suposat la creixença progressiva de la individualització i la desaparició gradual de les posicions adscrites. Aquest procés evidencia una homologia creixent entre els espais públic i privat, i sovint representa la fragilització dels vincles familiars com a resultat d'una institucionalitat molt més feble. Però alhora obre una porta a l'esperança, atès que implica la possibilitat de democratitzar les relacions familiars. En el nostre temps, l'aprofundiment de la democràcia privada constitueix una garantia sense precedents de cara a l'establiment d'una veritable democrà cia pública. 


\section{Bibliografia}

Alberdi, Inés; Flaquer, Lluís; I gLesIAS de U SSEL, Julio (1994). Parejas y matrimo nios: Actitudes, comportami entos y experiencias. M adrid: M inisterio de Asuntos Sociales.

Alm Ed A, Elisabet; Flaq UER, Lluís (1995). «L as familias monoparentales en España: Un enfoque crítico». Revista Internacional de Sociología, núm. 11, p. 21-45.

BARBAGLI, M arzio (1990). Provando e riprovando: M atrimonio, famiglia e divorzio in I ta lia ein altri paesi occidentali. Bolònia: II Mulino.

BECK, U Irich; BECK-GERn SH EIM, Elisabeth (1998). El normal caos del amor. Barcelona: El Roure.

ConTE, Edouard; F LAQUeR, Lluís (1983). «Propostes per a una millor explotació de les dades padronals dels municipis de C atalunya». Papers. Revista de sociologia, núm. 20, p. 199-227.

D on ATI, Pierpaolo (1998). M anuale di sociologia della famiglia. Roma-Bari: Laterza.

FLAQUER, Lluís (1978). «The 1977 Spanish Elections in a Small Town: A Study in Electoral Anthropology». University of Keele, Iberian Studies, 7, p. 49-53.

- (1979a). «Família i societat en un poble de la Garrotxa». U niversitat de Barcelona. Comentaris d'Antropologia Cultural, núm. 1, p. 16-19.

- (1979b). «Per a una sociologia de la família a C atalunya». Papers Revista de Socio logia, núm. 12, p. 171-182.

- (1982a). «Vers una sociologia de la privacitat». Papers Revista de sociol ogia, núm.17, p. 107-133.

- (1982b). Dela vida privada. Barcelona: Edicions 62.

- (1983). «ntroducció». A M ILL, J.S. Sobre la llibertat. Barcelona: Laia, p. 11-29.

- (1984a). «Evaluación crítica de las distintas metodologías para el estudio de las familias troncales campesinas». A SevilLa GuzM Án, Eduardo (ed.). Sobreagri cultoresy campesinos M adrid: Servicio de publicaciones agrarias, p. 251-272.

- (1984b). «Tres concepciones de la privacidad». Sistema, núm. 58, p. 31-44.

- (1984c). «Vot i carisma: Un estudi d'antropologia electoral». Barcelona: Estudis electorals, núm. 7, p. 253-276.

- (1986a). «Privatización o desprivatización? Contribuciones recientes a la sociología de la familia». Papers. Revista de Sociologia, núm. 27, p. 157-172.

- (1986b). «Family, Residence and Industrialisation in N orthern C atalonia: Legal and Social Aspects». Sociologia Ruralis, 26, p. 268-284.

- (1986c). «Prólogo» A H ARRIS, C.C. (ed.). Familia y sociedad industrial. Barcelona: Península, p. 5-8.

- (1988). «Las asechanzas del intimismo». Revista Española de Investigaciones Socio lógicas, núm. 43, p. 177-181.

- (1989). «La teoria social de Ferguson». A Ferguson, Adam. Assaig sobre la histò ria de la societat civil, pròleg a l'edició catalana. Barcelona: Edicions 62, p. 5-16.

- (1990). «La familia española: Cambio y perspectivas». A GInER, Salvador (ed.). España: Sociedad y política. Madrid: Espasa-Calpe, p. 509-549.

- (1991a). «iH ogares sin familia o familias sin hogar?: U n análisis sociológi co de las familias de hecho en España». U niversitat Autònoma de Barcelona, Papers Revis ta de Sociologia, núm 36, p. 57-78. 
- (1991b). «Anàlisi i propostes des de la perspectiva de la sociologia». A D inàmica social i factors intervinents en l'extensió de l'ús del català, Vol. 3 d'Estudis i propostes per a la difusió de l'ús social de la llengua catalana. Barcelona: D epartament de Cultura, Generalitat de C atalunya, p. 77-82.

- (1991c). «Voto y carisma: Un estudio de antropología el ectoral». A PRAT, Joan; Contreras, Jesús; M oren o, Isidoro (eds.). Antropología de los puebl os de España. M adrid: Taurus, p. 587-600.

- (1993a). «H omogamia, individual ismo y familia: M odelos de análisis para la formación de la pareja». A Ro IGÉ, Xavier (ed.). Perspectivas en el estudio del parentes co y la familia. Federación de las Asociaciones de Antropología del Estado español: Tenerife, p. 47-63; Revista Internacional de Sociología. Instituto de Estudios Sociales Avanzados, núm. 5, p. 69-85.

- (1993b). «La socialización en la familia: Teorías, modelos e interacciones». A G ARCíA de León, M aria Antonia; de LA Fuente, G loria; O RTEGA, Félix (eds.). Socio logía de la educación. Barcelona: Barcanova, p. 45-69.

- (1994a). «Economia i família». Q uaderns deServeis Socials. Barcelona: D iputació de Barcelona, núm. 7, juliol, p. 29-31.

- (1994b). «La familia como arena de contienda». Claves de razón práctica, núm. 46, octubre, p. 64-67.

- (1994c). «Llengua i espai públic». Revista de Catalunya, núm. 85, maig, p. 9-20.

- (1994d). «Llengua, identitat i modernitat». Revista de Catalunya, núm. 83, p. 20-32.

- (1995a). «El modelo de familia española en el contexto europeo». A SARASA, Sebastià; M O REN O, Luis (eds.). El Estado del bienetar en la Europa de sur. M adrid: Consejo Superior de Investigaciones C ientíficas/Instituto de Estudios Sociales Avanzados, p. 289-311.

- (1995b). «Família i canvi social en una vila de la C atalunya vella». Papers. Revista de Sociologia, núm. 45, p. 7-23.

- (1995c). «Família i desigualtat», A Flaquer, Lluís (ed.). Recull de ponències, Jornades sobre «Família i canvi social», Any Internacional de la Família 1994. Barcelona: Associació per a les N U a Espanya, p. 71-80.

- (1995d). «La familia y la sociedad europea del bienestar». A Enciclopedia de Euro pa, vol. I. Barcelona: Planeta, p. 114-119.

- (1995e). «La pareja como "arquitecto de la familia"». a A LBERDI, Inés (ed.). Infor me sobre la situación de la familia en España. M adrid: M inisterio deAsuntos Sociales, p. 192-203.

- (1995f ). «Las familias monoparentales en España y en Europa: D inámica interna». A Romero, Fermín (ed.). La figura del padre en las familias de las sociedades desarrolladas (Actas del si mposium internacional). Las Pal mas de G ran Canaria, p. 317-341.

- (1995g). «Las funciones social es de la familia». D ocumentación social: Revista de Estudios Sociales y de Sociología Aplicada, núm. 98, gener-març, p. 39-48.

- (1995h). «T rabajo y vida de pareja en las sociedades desarrolladas». A G ALD EAN 0 Aram en día, Jesús M. (ed.). La vida de pareja: Evolución y problemática actual. Salamanca: Editorial San Esteban, p. 205-212.

- (1996a). «Familia, desigualdad e identidad». Claves de razón práctica, núm. 61, abril, p. 46-52. 
- (1996b). «N oves famílies i canvi d'ordre social». Revista d'Etnologia de Catalunya, núm. 8, abril, p. 48-53.

- (1996c). El català, ¿llengua pública o privada? Barcelona: Empúries.

- (1997). «La emancipación familiar de los jóvenes». Revista de Estudios de Juven tud, p. 37-45.

- (1998a). El destino dela familia. Barcelona: Ariel.

- (1998b). «Prefaci: Família, gènerei comunitat». A GINER, S. (ed.). La societat cata lana. Barcelona: Institut d'Estadística de Catalunya, p. 397-399.

- (1998c). «Família i noves formes de convivència». A GIN ER, S. (ed.). La societat catalana. Barcelona: Institut d'Estadística de C atalunya, p. 401-415.

- (1998d). «Família, mercat i estat de benestar». A GINER, S. (ed.). La societat cata lana. Barcelona: Institut d'Estadística de Catalunya, p. 467-475.

- (1998e). «L'impacte de les noves tecnologies sobre la llengua i les seves dimensions pública o privada». A M OLLÀ, Toni (ed.). La política lingüística a la societat de la informació. Alzira: Edicions Bromera, p. 277-297.

- (1998f). Diversos articles. A GINER, S.; LAM O DE Espin osa, E.; TORRES. C. (eds.).Diccionario de Sociología. M adrid: Alianza editorial (J.J. BACH ofEN, Familia extensa, A. Ferguson, M onogamia, Privatización, Público/privado, F. TönNIES, C omunidad/sociedad, KIBBUTZ, C atalanismo, Ko LKH OZ, Consanguinidad, Incesto, Linaje, Parentela, Parentesco).

- (1999). La estrella menguante del padre. Barcelona: Ariel.

FlaQuer, Lluís; ALM EDA, Elisabet; JuRAD O, Teresa (en premsa). «Family Change and Family Policy in Spain». A FLo RA, Peter (ed.). Family Change and Family Policy in Southern Europe. O xford: 0 xford U niversity Press.

Flaquer, Lluís; Brullet, Cristina (1999). Polítiques familiars a Catalunya: U na pri mera aproximació. Barcelona: Fundació Jaume Bofill.

FlaQUER, Lluís; G INER, Salvador (1979). «Ferdinand Tönnies y la ciencia social moderna». A TÖNNIES, Ferninand, Comunidad y asociación, pròleg a la edició espanyola, Barcelona: Península, p. 5-22.

- (1982). «Unas sociedades europeas de difícil modernización», a Geografía de la sociedad humana, vol. 4, Barcelona: Planeta, p. 429-469.

- (1984). «Pròleg», a Ferdinand T ö N NIES. Comunitat i associació, pròleg a l'edició catalana. Barcelona: Edicions 62, p. 5-23.

Flaquer, Lluís; G In ER, Salvador; M OREN O, Luis (1990). «L a sociedad española en la encrucijada». A G IN ER, Salvador (ed.). España: Sociedad y política. M adrid: Espa sa-Calpe, p. 19-74.

FLAQU ER, Lluís; I GLESIAS DE U SSEL, Julio (1993). «Familia y análisis sociológico: El caso de España». Revista Española de Investigaciones sociológicas, núm. 61, p. 57-75.

- (1996). «T he Sociology of the Family in Spain: An Attempt at Interpretation», publicació simultània a M arriage \& Family Review, 23: 575-598; A Su SSM AN, M arvin B.; Stovall H an KS, Roma (eds.). Intercultural Variation in Family Research and Theory: Implications for Cross $\mathrm{N}$ ational Studies. N ova York: The H aworth Press, p. 575-598.

FlaQuer, Lluís; M ASATS, M arta; M endizÁBAL, Enric; Pujadas, Isabel (1992). Aspec tes demogràficsi característiquesfamiliarsi relacionals, volum I de l'I nforme $G$ ene ral del'«Enquesta de la Regió M etropolitana de Barcelona 1990: Condicions de vida i hàbits de la població». Barcelona: Institut d'Estudis M etropolitans. 
Flaquer, Lluís; Soler, Joan (1990). Permanencia y cambio en la familia española, $M$ adrid: Centro de Investigaciones Sociológicas.

FlaqueR, Lluís; SO LSO NA, M ontserrat (1995). «La situació de la família a Barcelona». Barcelona Societat, núm. 3, p. 12-37.

Giner, Salvador; Flaquer, Lluís; Busquet, Jordi; BultÀ, Núria (1996). La cultura cata lana: el sagrat i el profà, Barcelona: Edicions 62.

Giner, Salvador; Flaquer, Lluís; H O M S, O riol; SARASA, Sebastià (1998). «C atalunya a la cruïlla». A GIN ER, S. (ed.). La societat catalana. Barcelona: Institut d'Estadística de Catalunya, p. 25-39.

H ARRIS, C.C. (1983). The Family and Industrial Society. Londres: George Allen \& Unwin (Versió castellana: H arris, C.C. (1986). Familia y sociedad industrial, Barcelona: Península).

I GLESIAS DE U SSEL, Julio; FLAQUER, Lluís (1996). «T he Family and Sociological Analysis: The C ase of Spain». M adrid: C entro de Investigaciones Sociológicas/Revista Española de Investigaciones Sociológicas (English edition 1996), p. 113-130.

I GLESIAS DE U SSEL, Julio; FLAQUER, Lluís; M EIL, Gerardo i altres, (1994). «Familia». A V Informe sociológico sobre la situación social en España: Sociedad para todos el el año 2000. M adrid: Fundación Foessa, p. 415-547.

KeLLERH ALS, J. i al tres. (1982). M ariages au quotidien: Inégalités sociales, tensionscultu relles et organisation familiale. Lausanne: Éditions Pierre-M arcel Favre.

LASLETT, Peter; WaLL, Richard (eds.) (1972). H ousehold and Family in Past Time, Cambridge: Cambridge U niversity Press. 